distributed broadcast over the whole country, and studied with care by all ophthalmic surgeons and by those who have anything to do, officially or voluntarily, with the care of the blind.

The remarks on prevention alone are worthy of wide dissemination.

Dr. Freeland Fergus and his colleagues are to be congratulated on an extremely valuable piece of work.

It is to be regretted that no indication is given as to where the report can be obtained or of its price.

\title{
THE OPTICAL CONVENTION
}

The Optical Convention was held at the Imperial College of Science and Technology, South Kensington, from April 12 to April 17. This was the third Optical Convention, the first having been held in 1905 and the second in 1912. The Convention of 1926 met under the presidency of the Astronomer Royal, Sir Frank Dyson, and was highly successful in dealing with a full and varied programme. The Transactions will form a very valuable record of the present position of the science and industry of optics in this country. The war, by throwing us on our own resources, caused us to make great advances in the production of optical apparatus, and thus enabled us to go far to regain the leadership that was rapidly passing into German hands.

While some of the papers were directly concerned with ophthalmic work, all contained some points of interest to the ophthalmologist. Professor Elliot Smith gave an interesting account of the eye and its functions in which he traced man's intellectual superiority to the evolution of his visual sense. Messrs. Chance and Hampton read a paper on the practical side of the manufacture of optical and tinted glass which included an account of a glass that had been produced after twenty years of experiment to serve as a filter that gave a spectroscopically correct colour match when used with a half-watt lamp. Of the various papers specially concerned with ophthalmic work that of Messrs. Hartridge and Lythgoe on the influence of illumination on visual acuity; of $\mathrm{Mr}$. Fincham on the mechanism of accommodation; and that of $\mathrm{Mr}$. Taylor on the fitting of glasses in cases of facial asymmetry were specially noteworthy. We hope to be able to give abstracts of some of the papers when published.

Especially noticeable was the collection of early telescopes, astrolabes, etc. The dispensing opticians held a remarkably fine exhibition of ophthalmic wares in a large room in the basement. 
The Mayou and Fincham slit-lamps were on view as well as the latest improvements in apparatus for fusion training. Moses Primrose, had he attended, would not have been satisfied with a gross of green spectacles with copper rims and shagreen cases; but would doubtless have ordered specimens of all the tinted glasses present!

The lighter side of the subject was not neglected and there were actually long queues at the doors to see the various optical illusions. The exhibition was highly successful and well attended, and, even if some of the public came more to be amused than to be instructed, the entertainment must have served a useful purpose in demonstrating the capacities of modern optical science.

\section{ABSTRACTS}

\section{I.-DETACHMENT OF THE RETINA}

(I) Weekers, L. (Liège).-Experimental detachment of the retina. (Décollement rétinien expérimentale.) Arch. d'Ophtal., June, 1925.

(1) This paper, presented to the Société française d'Ophtalmologie, in May, 1925, is a valuable contribution to our knowledge of "idiopathic detachment," especially as to its pathogenesis. As the paper extends to more than 30 pages an adequate abstract would exceed the usual limit, hence this brief notice.

Weekers recounts the results of his experiments on animals, in which by superficial cauterization of the exposed sclerotic, he has induced detachment of the retina resembling in almost every detail that observed in man in cases of (usually) unexplained simple detachment. He describes the histological changes in these eyes excised at periods varying from twenty minutes to weeks after the initial experiment, and numerous photographic reproductions of sections are given.

"The results of experiment enlighten us as to the conditions requisite for the production of a retinal detachment of which the evolution is identical with that of idiopathic detachment. To induce detachment all that is essential is a very limited area of congestion of the choroid, provided that the congestion is acute. There follows an intra-retinal oedema and a separation of the retina limited at first to the site of the choroidal lesion but extending rapidly if the lesion be situated in the upper part of the globe."

The author devotes close attention to the relation between intraocular pressure and detachment of the retina. In his experiments 